\title{
Anti-Ro(SSA) Autoantibodies Are Associated with T Cell Receptor $\beta$ Genes in Systemic Lupus Erythematosus Patients
}

\author{
Mark Barton Frank, ${ }^{\star}$ Robert McArthur, ${ }^{\star * 5}$ John B. Harley, ${ }^{\star \neq 5}$ and Atsushi Fujisaku* \\ ${ }^{*}$ Arthritis and Immunology Program, Oklahoma Medical Research Foundation; ${ }^{\ddagger}$ Department of Medicine, University of Oklahoma \\ Health Sciences Center; and ${ }^{\S}$ Veterans Administration Hospital, Oklahoma City, Oklahoma 73104
}

\begin{abstract}
Several of the heterogeneous clinical manifestations of systemic lupus erythematosus have been associated with specific autoantibodies. Associations between HLA class II antigens and autoantibodies to the ribonucleoproteins Ro(SSA) and La(SSB) have been reported in these patients. Because HLA class II molecules present antigen to $T$ cell receptors (TCRs), we have searched for a TCR gene associated with the production of anti-Ro(SSA) antibodies. A pair of restriction fragment length polymorphisms (RFLPs), one of which hybridizes to the TCR constant region $C \beta 1$ and the other to the $C \beta 2$ gene, has been identified, suggesting these may be genotypic markers for an extended region of the TCR $\beta$ locus. This RFLP pair occurs in $76 \%$ of patients with $\mathrm{Ro}(\mathrm{SSA})$ precipitins, $84 \%$ of antiRo(SSA)-positive patients lacking La(SSB) precipitins, but only $41 \%$ of the patients lacking both precipitins $(P=0.0004)$. This disproportionate occurrence in a subset of lupus patients indicates that these RFLPs are not disease susceptibility markers, but rather are important markers for TCR genes whose products are involved in the production of anti-Ro(SSA) antibodies. The majority of patients who have these RFLPs and HLA class II antigens previously associated with the antiRo(SSA) response make this antibody, suggesting that interactions between products of these loci occur in response to Ro(SSA). (J. Clin. Invest. 1990. 85:33-39.) autoantibody • restriction fragment length polymorphism - Ro(SSA) - systemic lupus erythematosus $\bullet T$ cell receptor
\end{abstract}

\section{Introduction}

Systemic lupus erythematosus (SLE) ${ }^{1}$ is a rheumatic disease of unknown etiology and complex pathogenesis. Its study is complicated by diverse clinical manifestations and heterogeneous laboratory findings. Abundant evidence has shown the importance of genetic contributions to the development of lupus. A several hundredfold increase in the incidence of the disease in relatives of patients compared with the general pop-

Address correspondence to Dr. Bart Frank, Arthritis and Immunology Program, Oklahoma Medical Research Foundation, 825 N.E. 13th St., Oklahoma City, OK 73104.

Received for publication 13 June 1989 and in revised form 7 September 1989.

1. Abbreviations used in this paper: $\mathrm{C} \beta$, constant region gene of a TCR $\beta$ locus; RFLP, restriction fragment length polymorphism; SLE, systemic lupus erythematosus; TCR, $\mathrm{T}$ cell receptor; $\mathrm{V} \beta$, variable region gene of the TCR $\beta$ locus.

J. Clin. Invest.

(c) The American Society for Clinical Investigation, Inc.

0021-9738/90/01/0033/07 \$2.00

Volume 85, January 1990, 33-39 ulation exists $(1,2)$, and a high concordance in monozygotic vs. dizygotic twins has been reported $(3,4)$. Associations between the HLA class II antigens HLA-DR2, -DR3, and -DR7 with the disease exist (5-8). Because of linkage disequilibrium between these loci and others in the HLA region, it remains to be determined whether these or alleles at other linked loci are most closely associated with disease predisposition (8-13). Recent work indicates that not only the disease as a whole, but also the presence of particular lupus autoantibodies are associated with histocompatibility genes (14-18).

$\operatorname{Ro}(S S A)$ is a ribonucleoprotein particle consisting of a polypeptide chain of $\sim 60 \mathrm{kD}$ associated with one of four small (83-112 base) RNA molecules (19-22). This complex, whose function is currently unknown, is present in all mammalian cells that have been studied. Anti-Ro(SSA) autoantibodies are typically found in 30-50\% of lupus patients and in up to $96 \%$ of patients with primary Sjogren's syndrome (21, 23). In lupus patients these antibodies are associated with lymphopenia, photosensitive dermatitis, and pulmonary disease $(15,17,24-27)$. Antibodies against Ro(SSA) are enriched in acid eluates of nephritic kidneys of lupus patients when compared with their serum antibody levels, suggesting their role in lupus nephritis (28). Exogenous anti-Ro(SSA) antibodies deposit in human skin grafts on severe combined immune deficiency mice in patterns similar to those seen in skin lesions of subacute cutaneous lupus patients (29). The close association of maternal anti-Ro(SSA) with neonatal dermatitis and complete congenital heart block further suggests a pathogenic role for these antibodies (30-32).

Patients with $\mathrm{La}(\mathrm{SSB})$ precipitins constitute a subset of those with $\mathrm{Ro}(\mathrm{SSA})$ precipitins. This patient subset differs in the frequencies of the HLA-DR2 and -DR3 antigens when compared with those having only anti-Ro(SSA) precipitins $(11,15)$. In lupus patients the mutual occurrence of both antibodies is associated with a low frequency of renal disease when compared with patients with only anti-Ro(SSA) antibodies $(17,24)$, and a high prevalence of photosensitivity, discoid rash, and sicca symptoms $(23,24,33,34)$. In the absence of cytotoxic chemotherapy, the presence of both of these antibodies is stable irrespective of disease activity (24). These findings suggest that genetic and clinical differences exist between the anti-Ro(SSA)-positive patients with and without the anti$\mathrm{La}$ (SSB) autoantibody, and patients lacking the anti-Ro(SSA) antibodies.

Anti-Ro(SSA) autoantibodies in lupus patients have been associated with HLA class II antigens (14-16, 18, 35, 36). In models of $\mathrm{T}$ cell activation, antigen is presented by MHC proteins to the $T$ cell receptor (TCR). However, no investigations have shown differences between TCR genes of lupus patients and healthy controls (37-39). These studies have considered lupus as a single disease entity without consideration of the heterogeneous antibody profiles or HLA class II differences of these patients, and therefore do not mean that important rela- 
tionships with TCRs do not exist. In this study we have investigated the role of TCRs in the production of anti-Ro(SSA) antibodies. The immunologically defined subgroup of patients with this autoantibody is more homogeneous genetically and clinically than the group of lupus patients as a whole. The combination of a new restriction fragment length polymorphism (RFLP) with the previously described Bgl II TCR $\beta$ RFLP permitted us to identify a genotypic marker that is strongly associated with anti-Ro(SSA) autoantibodies. Our data further suggested that a TCR gene product may interact with particular HLA class II antigens in the development or perpetuation of this autoimmune response. This is the first example of an association between a TCR gene and an immune response to a known autoantigen in humans.

\section{Methods}

DNA probes. Human TCR $\beta$ cDNA (40) subcloned in pBR322 was graciously provided by J. D. Capra (University of Texas Southwestern Medical Center, Dallas, TX). The 770-bp Pst I insert was electrophoretically isolated from the plasmid DNA and digested with Bgl II. A $\sim 400$-bp fragment that contained the first, second, and a few nucleotides of the third exon of the TCR $\beta$ constant region $(C \beta)$ was ligated into the pUC19 vector and transformed into the Escherichia coli strain TB1 (41). This TCR C $\beta$ insert was isolated using a preparative 5\% $N, N^{\prime}$-bis-acrylylcystamine crosslinked polyacrylamide gel (Bio-Rad Laboratories, Richmond, CA) and DEAE-cellulose ion-exchange chromatography, and used as a probe in this study.

Patients and DNA protocols. A minimum of $30 \mathrm{ml}$ of anticoagulated peripheral blood was collected from 70 female and 6 male patients diagnosed with SLE (42). The average patient age was $40.6 \mathrm{yr}$, with a range of 22-80 yr. 46 patients were Caucasians, 26 were Black, 3 were American Indians, and 1 was Chinese. Peripheral blood samples were also collected from 25 healthy individuals. No one in the latter group was known to have SLE in their family. The frequency of the RFLPs did not vary with the age or sex of the participants. The frequency of one RFLP (the Bgl II 9.8-kb RFLP) was slightly increased in Blacks when compared with Caucasians. No racial differences were noted in the frequency of the Kpn I RFLPs or in the frequency of the combined Bgl II 9.8- and Kpn I 1.75-kb RFLP in controls or in patients who produced the anti-Ro autoantibody when grouped by race. Because of these preliminary findings and the small number of individuals present in racially and autoantibody-defined groups, patients were pooled irrespective of age, sex, or race in this study.

Buffy coat leukocytes were lysed with $1 \%$ Triton X-100 (Aldrich Chemical Co., Milwaukee, WI) in $0.32 \mathrm{M}$ sucrose, $10 \mathrm{mM}$ Tris- $\mathrm{HCl}$, and $5 \mathrm{mM} \mathrm{MgCl} 2, \mathrm{pH}$ 7.5. The centrifugal pellet was resuspended in 75 $\mathrm{mM} \mathrm{NaCl}$ and $25 \mathrm{mM}$ EDTA and digested with $200 \mu \mathrm{g} / \mathrm{ml}$ proteinase $\mathrm{K}$ (Bethesda Research Laboratories, Gaithersburg, MD) in 0.5\% SDS at $37^{\circ} \mathrm{C}$ overnight. The following day, $5 \mu \mathrm{g}$ RNAse (Sigma Chemical Co., St. Louis, MO) was added for $30 \mathrm{~min}$, followed by four phenol$\mathrm{CHCl}_{3}$-isoamyl alcohol extractions and ethanol precipitation. The isolated DNA was resuspended in $1 \mathrm{ml}$ of $10 \mathrm{mM}$ Tris- $\mathrm{HCl}$ and $1 \mathrm{mM}$ EDTA.

10- $\mu$ g samples of DNA were digested with restriction enzymes in buffer provided by the enzymes' suppliers (Promega Biotech [Madison, WI], Boehringer Mannheim Biochemicals [Indianapolis, IN], and Bethesda Research Laboratories). Samples were subjected to electrophoresis in $0.8 \%$ agarose gels in TBE buffer $(0.1 \mathrm{M}$ Tris, $0.1 \mathrm{M}$ boric acid, and $2 \mathrm{mM}$ EDTA at $\mathrm{pH} 8.0$ ) at $40 \mathrm{~V}$ for $16-18 \mathrm{~h}$. DNA was transferred to nylon membranes (Amersham Corp. [Arlington Heights, IL] or Gelman Sciences, Inc. [Ann Arbor, MI) by the method of Southern (43), and prehybridized for $4 \mathrm{~h}$ at $65^{\circ} \mathrm{C}$ in $5 \times \operatorname{SSPE}(0.75$ $\mathrm{M} \mathrm{NaCl}, 50 \mathrm{mM} \mathrm{NaH} \mathrm{PO}_{4} / \mathrm{H}_{2} \mathrm{O}, 5 \mathrm{mM}$ EDTA, pH 7.0), $10 \times$ Denhardt's solution $(0.2 \%$ BSA, $0.2 \%$ ficoll, $0.2 \%$ polyvinylpyrrolidone), $5 \%$ dextran sulfate, $0.1 \%$ SDS, $50 \mathrm{mM}$ phosphate buffer, and $50 \mu \mathrm{g} / \mathrm{ml}$ of denatured salmon sperm DNA. The prehybridization solution was replaced with fresh solution and hybridization was performed overnight at $65^{\circ} \mathrm{C}$ with the radiolabeled TCR C $\beta$ probe $(44,45)$. Membranes were washed at high stringency with $0.2 \times$ SSPE and $0.1 \%$ SDS at $65^{\circ} \mathrm{C}$. Sizes of RFLP bands were estimated by autoradiography (X-Omat AR film; Eastman Kodak Co., Rochester, NY) relative to the migration of Hind III-digested lambda bacteriophage DNA and Hae III-digested phiX-174 DNA (Bethesda Research Laboratories, Gaithersburg, MD).

Detection of patient autoantibodies. Patient sera were analyzed for the presence of anti-Ro(SSA) and anti-La(SSB) antibodies against bovine spleen extracts relative to reference sera by Ouchterlony immunodiffusion and counter immunoelectrophoresis $(19,24)$.

Statistical analysis. Statistical analysis of RFLPs was carried out using Fisher's exact test with the Epistat software package for PC-based computer systems (T. Gustafson, Round Rock, TX). The chi-square test was used to test for homogeneity and genotypic differences between groups. Statistical levels of confidence are shown without adjustment for the number of comparisons made.

\section{Results}

In preliminary experiments DNA from 13 patients was digested with the restriction enzymes Bgl II, Eco RI, Eco RV, Hind III, Kpn I (or its isoschizomer Asp 718), Pst I, Pvu II, and Taq I. Polymorphic bands hybridizing to the human TCR C $\beta$ probe were only detected after digestion with Bgl II or Kpn I. The paucity of TCR $\beta$ RFLPs in these patients is consistent with that observed in a previous report in healthy individuals (46). The enzyme Bgl II produced 9.8- and 8.8-kb polymorphic fragments and a $1.2-\mathrm{kb}$ fragment present in all individuals. Digestion with Kpn I revealed 5.6- and 1.75-kb polymorphic fragments and a 7.1-kb constant fragment. The Bgl II RFLP has been shown to be inherited as an allelic variant (39, 46-48). Family studies in our laboratory confirm that both the Bgl II and Kpn I RFLPs are inherited as alleles of a single autosomal locus (data not shown). During the course of this work, Oksenberg et al. (47) reported that Kpn I RFLPs similar in size to those we observed were inherited as alleles in three families.

The location of the polymorphic Bgl II restriction site has been determined $(46,48,49)$. Invariant Bgl II sequences are present in the first exon of the $C \beta 1$ and $C \beta 2$ genes, while the Bgl II site 678 nucleotides $5^{\prime}$ of the $C \beta 2$ invariant site is polymorphic. Therefore, the Bgl II RFLPs are a result of hybridization of the TCR $C \beta$ probe to the $C \beta 1$ gene. To determine the location of the Kpn I polymorphic site we initially searched a computer data base for human TCR $\beta$ nucleotide sequences and located Kpn I sites between the second and third exons of the $C \beta 1$ and $C \beta 2$ genes (49). A third Kpn I site was found 1.8 kb $5^{\prime}$ of the Kpn I sequence in the intron of the $C \beta 2$, but not the $C \beta 1$ gene. Because this is similar in size to one of the Kpn I RFLPs we observed, we used the presence of the polymorphic Bgl II site in this region to test the hypothesis that the Kpn I RFLPs are due to hybridization of the TCR C $\beta$ probe to the $\mathrm{C} \beta 2$ gene. Double digestions using Kpn I and Bgl II produced three fragment sizes. A $0.91-\mathrm{kb}$ fragment was detected in everyone and corresponded to the probe hybridizing to the $C \beta 1$ gene (Fig. 1). The polymorphic 0.98 - and 1.05 -kb fragments found in individuals with the Kpn I 1.75- and 5.6-kb RFLPs, respectively, were as predicted if the polymorphic Kpn I site occurs between the second and third $C \beta 2$ exon. Because the TCR C $\beta$ probe used lacked the fourth and nearly all of the 


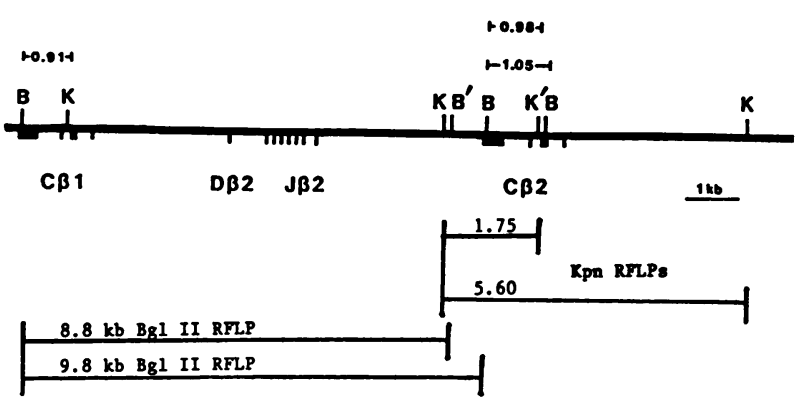

Figure 1. Restriction enzyme map of the Bgl II and Kpn I recognition sites in the TCR C $\beta$ loci. Exon positions are indicated below the horizontal line and restriction enzyme sites above the line. $B$, Bgl II site; $K, \mathrm{Kpn} I$ site. $\mathrm{B}^{\prime}$ and $\mathrm{K}^{\prime}$ indicate positions of polymorphic sites for the Bgl II and Kpn I enzymes, respectively. Molecular sizes of TCR C $\beta$ polymorphic fragments after double digestion with both enzymes are shown at the top of the figure.

third constant region exons, no hybridization was detected after Kpn I digestion with DNA 3' of the C $\beta 1 \mathrm{Kpn}$ I site or with the homologous portions of the $C \beta 2$ gene in individuals with the 1.75-kb Kpn I RFLP. Therefore, while the Bgl II RFLPs were detected by hybridization of the probe with the $C \beta 1$ gene, the Kpn I RFLPs were due to hybridization with the $C \beta 2$ gene. This suggests that combinations of these RFLPs may be useful as markers for an extended region of this portion of the genome, which includes not only exons coding for constant portions of $\mathrm{T}$ cell receptor polypeptides, but for variable regions $(\mathrm{D} \beta$ and $\mathrm{J} \beta$ ) as well.

Because strong associations between HLA class II region markers and anti-Ro(SSA) antibodies have been described in lupus patients, we wished to determine if the markers for the TCR genes we identified might be useful in detecting associations between TCR $\beta$ genes and the anti-Ro(SSA) response. An increase in the allelic frequency of the $\mathrm{Bgl}$ II $9.8-\mathrm{kb}(P=0.05)$ as well as the $\mathrm{Kpn} I 1.75-\mathrm{kb}(P=0.05)$ RFLP was found in the 42 patients with the Ro(SSA) precipitin when compared with the 34 patients who lacked this precipitin (Table I). Genotypi-

Table I. Allele and Genotype Distributions of TCR C R RFLPS

\begin{tabular}{|c|c|c|c|c|}
\hline \multirow[b]{3}{*}{ Group } & \multicolumn{4}{|c|}{ Allelic distributions } \\
\hline & \multicolumn{2}{|c|}{$\begin{array}{l}\text { Patients with Bgl II } \\
\text { alleles }\end{array}$} & \multicolumn{2}{|c|}{$\begin{array}{l}\text { Patients with } \\
\text { Kpn I alleles }\end{array}$} \\
\hline & 9.8 & 8.8 & 5.6 & 1.75 \\
\hline Rot & 37 & 23 & 24 & 36 \\
\hline Ro- & 24 & 27 & 21 & 23 \\
\hline
\end{tabular}

\begin{tabular}{lccccccc} 
& \multicolumn{5}{c}{ Genotypic distributions } \\
\cline { 2 - 4 } \cline { 3 - 4 } \cline { 6 - 8 } Group & $9.8 / 9.8$ & $9.8 / 8.8$ & $8.8 / 8.8$ & & $5.6 / 5.6$ & $5.6 / 1.75$ & $1.75 / 1.75$ \\
\hline Ro+ & 19 & 18 & 5 & 6 & 18 & 18 \\
Ro- & 7 & 17 & 10 & & 11 & 10 & 13
\end{tabular}

The numbers of patients with each allele and genotype in each group are shown. The total number of individuals in the Ro+ and Rogroups are 42 and 34, respectively.
Table II. Combination of Bgl II 9.8-kb RFLP and Kpn I 1.75-kb RFLP

\begin{tabular}{ccccc}
\hline & \multicolumn{3}{c}{ RFLP combination } & \\
\cline { 2 - 5 } Anti-Ro & Present & Absent & Total & $P$ \\
\hline+ & 32 & 10 & 42 & - \\
- & 14 & 20 & 34 & 0.002 \\
\hline
\end{tabular}

The number of individuals in which the RFLP pair is present or absent is shown for each group. $P$ values were calculated using Fisher's exact test.

cally, Bgl II 9.8-kb homozygotes occurred more frequently in the Ro(SSA) precipitin-positive group $(P=0.02)$. However, these differences were not statistically significant after multiplying the probability values by the number of comparisons made.

When analyzed together, the Bgl II and Kpn I RFLPs may act as a marker for an extended region of the TCR $\beta$ locus, and otherwise identify genes that are important in the recognition of the Ro(SSA) autoantigen. Consistent with this hypothesis, we noted that 32 of the 37 patients with the Ro(SSA) precipitin who had the Bgl II 9.8-kb RFLP (Table I) also had the Kpn I 1.75-kb RFLP. Table II shows that the combination of these two RFLPs was present in $76 \%$ of the patients with Ro(SSA) precipitins. In contrast, it occurred in only 14 of 34 patients (41\%) lacking this precipitin, resulting in a highly significant difference between these two patient groups $(P=0.002)$.

When all 76 lupus patients were considered as a single group, the frequency of these two Bgl II and Kpn I RFLPs did not differ from that found in 25 healthy subjects (Table III). These results are consistent with those of others who have failed to find differences when comparing the Bgl II RFLPs between SLE patients and controls (37-39). The joint occurrence of these two RFLPs does not, therefore, appear to be a risk factor for the disease. Rather, the RFLP combination is a marker for TCR $\beta$ genes involved in the production of antiRo(SSA) antibodies in a subset of lupus patients (Table III).

We have initiated experiments to determine whether the Bgl II 9.8- and Kpn I 1.75-kb markers preferentially occur on the same chromosome in lupus patients with the anti-Ro(SSA) precipitins. Of the Ro(SSA) precipitin-positive patients studied with both of these RFLPs, the linkage phase of these markers is in coupling (i.e., on the same chromosome) in 24 patients, and in repulsion (i.e., opposite chromosomes) in only 2 patients. However, these markers also occur on the same chromosome

Table III. Combination of Bgl II 9.8-kb RFLP and Kpn I 1.75-kb RFLP

\begin{tabular}{lcccc}
\hline & \multicolumn{3}{c}{ RFLP combination } \\
\cline { 2 - 4 } \multicolumn{1}{c}{ Group } & Present & Absent & Total & $P$ \\
\hline SLE patients & 46 & 30 & 76 & - \\
Healthy subjects & 13 & 12 & 25 & 0.30
\end{tabular}

The number of individuals in which the RFLP pair is present or absent is shown for each group. $P$ values were calculated using Fisher's exact test. 
in 9 of the $15 \mathrm{Ro}(\mathrm{SSA})$ precipitin-negative patients that we have studied. Fully informative pedigrees must be analyzed from additional patients before definitive results can be reached on this issue. However, these findings suggest that the mere presence of these RFLPs on the same chromosome is not sufficient for production of the anti-Ro(SSA) antibodies in lupus patients. Detection of a functional TCR $\beta$ exon that codes for a TCR polypeptide recognizing the Ro(SSA) autoantigen will be required to determine whether these two RFLP markers are in linkage disequilibrium with such a gene.

As discussed in the introduction, patients with the Ro(SSA) precipitin differ genetically at HLA loci and clinically from patients with both the $\mathrm{Ro}(\mathrm{SSA})$ and $\mathrm{La}(\mathrm{SSB})$ precipitins. We have, therefore, divided the Ro(SSA)-positive patients into two groups based on the presence or absence of $\mathrm{La}(\mathrm{SSB})$ precipitins. A homogeneity chi-square test of the combined presence of the Bgl II 9.8- and Kpn I 1.75-kb RFLPs revealed significant differences between these two patient subsets ( $P$ $<0.05$ ), suggesting on the basis of these RFLPs that patients in these groups should not be pooled. As expected in a cohort of this size (76 patients), the number of patients with both precipitins is small, and therefore conclusions regarding this particular subgroup should be considered tentative. Table IV shows that the proportion of patients with Ro(SSA) and $\mathrm{La}$ (SSB) precipitins who have both the Bgl II 9.8- and Kpn I 1.75-kb RFLPs is more similar to that found in patients lacking the $\operatorname{Ro}(\mathrm{SSA})$ precipitin $(P=0.33)$ than to patients with just the Ro(SSA) precipitin $(P=0.06)$. These two RFLPs occur in $84 \%$ of the patients with only the Ro(SSA) precipitin, thus reducing the probability eightfold $(P=0.0004)$ compared with that observed when Ro(SSA)-positive and -negative patients, irrespective of their $\mathrm{La}(\mathrm{SSB})$ precipitin status were analyzed above. Of the $32 \mathrm{Ro}(\mathrm{SSA})$ precipitin-positive patients with both of these RFLPs, 26 of them lacked La(SSB) precipitins. Due to sample size, these findings suggest, but do not prove, that the group of $\operatorname{Ro}(\mathrm{SSA})$ precipitin-positive patients lacking $\mathrm{La}$ (SSB) precipitins are responsible for the differences between the Ro(SSA) precipitin-positive and -negative patients.

High titers of anti-Ro(SSA) antibodies have previously been described in HLA-DQ1/DQ2 heterozygous patients with primary Sjogren's syndrome and $\operatorname{SLE}(14,17)$. In this patient cohort, 11 of the $26(42 \%)$ HLA typed patients with only the anti-Ro(SSA) precipitin are HLA-DQ1/DQ2 heterozygotes, compared with only 2 of $22(9 \%)$ HLA-DQ typed antiRo(SSA)-negative patients $(P=0.01)$. If the TCR RFLPs are indeed markers for functional genes that recognize the

Table IV. Combination of Bgl II 9.8-kb RFLP and Kpn I 1.75-kb RFLP

\begin{tabular}{ccrrrrrr}
\hline \multicolumn{2}{c}{ Precipitin } & & \multicolumn{4}{c}{ RFLP combination } & \\
\cline { 5 - 6 } Anti-Ro & Anti-La & & Present & Absent & Total & $P$ \\
\hline- & - & & 14 & 20 & 34 & \\
+ & - & & 26 & 5 & 31 & 0.0004 \\
+ & + & & 6 & 5 & 11 & 0.33 \\
\hline
\end{tabular}

The number of individuals in which the RFLP combination is present or absent is shown for each group. $P$ values were calculated using Fisher's exact test when compared with the Ro(SSA) precipitin-negative patients.
Ro(SSA) antigen in conjunction with HLA class II molecules, one would expect to find an association between these TCR markers and these HLA-DQ antigens in Ro(SSA) precipitinpositive but not -negative patients. The Ro(SSA) precipitin was found in 20 of 24 patients $(83 \%)$ with the HLA-DQ1 antigen who also had the TCR $\beta$ RFLP markers, but in only 4 of the Ro(SSA) precipitin-negative patients with these markers $(P=0.004)$. The DQ2 serotype $(P=0.065)$ and DQ1/DQ2 heterozygosity $(P=0.013)$ were less strongly associated with these markers. The frequency of the joint occurrence of the HLA-DQ1 serotype and the TCR $\beta$ RFLPs in healthy individuals was similar to that in the Ro(SSA) precipitin-negative patients $(P=0.39)$. An association of this nature is not expected if the TCR $\beta$ RFLPs are not markers for a functional TCR gene or regulatory element involved in TCR gene expression. These studies suggest the existence of a multigenic interaction between products of these loci in the generation of anti-Ro(SSA) antibodies.

\section{Discussion}

In this study we identified TCR $\beta$ RFLPs that occur in a disproportionately high frequency in a subset of SLE patients with anti-Ro(SSA) antibodies. The majority of these patients lack anti-La(SSB) antibodies. Since no differences were found with respect to these RFLPs between patients when considered as a single group and healthy subjects, these RFLPs appear to be markers for the production of specific autoantibodies in lupus rather than risk factors for the disease. In studies by others the presence of Ro(SSA) and $\mathrm{La}(\mathrm{SSB})$ precipitins has been associated with clinical and genetic differences among lupus patients $(11,15,17,24-26)$. Given findings of the pathophysiologic significance of anti-Ro(SSA) antibodies in lupus, these results suggest a role for TCR genes in the disease process.

Five patients who make only anti-Ro antibodies lack the Bgl II 9.8- and Kpn I 1.75-kb RFLPs. This finding and the observation that this RFLP combination is present in nearly half of all participants without detectable levels of antiRo(SSA) antibodies suggest that the RFLP markers themselves are neither necessary nor sufficient for the anti-Ro(SSA) response. This is not surprising considering that the nucleotide sequence differences of either of these polymorphic sites do not occur in coding regions, and therefore do not alter the amino acid sequence of TCR $\beta$ polypeptides. We hypothesize that these RFLPs are genotypic markers for a TCR V $\beta, D \beta$, or $\mathrm{J} \beta$ gene coding for the variable portion of a TCR molecule that recognizes the Ro(SSA) antigen in patients with the Ro(SSA) precipitin. The lack of a complete association between this precipitin and the RFLP markers for this functional gene may be due to a number of possibilities. The absence of an appropriate HLA-encoded antigen-presenting molecule is the most attractive hypothesis, although other possibilities must be considered. Recombination may occur between these markers and the putative anti-Ro(SSA) TCR gene, or a second TCR $\beta$ gene may be involved with the production of anti-Ro(SSA) antibodies in some patients. Each of these hypotheses is testable once such a functional gene is identified. We may also have failed to detect low levels of anti-Ro(SSA) or anti-La(SSB) antibodies in some of the patients studied with the immunoprecipitation methods used here. Given the random rearrangement of $\mathrm{V} \beta$-D $\beta$-J $\beta$ exons as well as $N$-region diversity in the formation of a functional TCR variable region gene, it may be unusual to 
find absolute associations between expressed TCR genes and human diseases in random populations.

Whether these two polymorphic sites are markers for one or more than one region in the TCR gene complex cannot be determined from existing data. This RFLP pair may be a marker for a particular TCR $\beta$ variable gene component. The close proximity of the $\mathrm{D} \beta$ and $\mathrm{J} \beta$ genes to these markers makes them more likely candidates than $\mathrm{V} \beta$ genes. Coding sequences of the $\mathrm{D} \beta$ and $\mathrm{J} \beta$ genes have been shown to be of critical importance by Rupp et al., who have demonstrated that differences in these coding regions confer differential specificity to TCR molecules that have otherwise identical $\mathrm{V} \beta$ sequences (50). While recombination has been found between $V \beta$ and $C \beta$ genes (51), evidence for linkage disequilibrium between at least a portion of the $\mathrm{V} \beta$ genes and certain $\mathrm{V} \beta$ and $\mathrm{C} \beta$ genes has been reported (52), suggesting the possibility that these RFLPs may be a marker for a TCR V $\beta$ gene. However, the weakness of the latter association may imply that genes other than those in $\mathrm{V} \beta$ families are responsible for the findings reported here. Currently, data suggesting that specific $\mathrm{V} \beta$ sequences are expressed in a particular immune response remain controversial. On the one hand, different $\mathrm{V} \beta$ sequences have been reported in murine MHC-restricted $\mathrm{T}$ cell clones that respond to defined peptide determinants $(53,54)$, suggesting that TCR variable genes alone are not responsible for specificity. In contrast, specific $\mathrm{V} \beta$ genes seem to be preferentially utilized in murine experimental allergic encephalomyelitis and collagen-induced arthritis (54-57). While the few weak associations of $\mathrm{V} \beta$ genes are at the disease rather than the autoantibody level, characterization of specific autoantigens and the $T$ cells that respond to them is needed to determine what roles specific TCR V $\beta$ genes play in lupus and other human autoimmune disorders characterized by autoantibodies. Finally, one of these RFLPs may be associated with regulatory rather than coding elements in or adjacent to the TCR C $\beta$ exons. Recently, Krimpenfort et al. identified a TCR enhancer located downstream of the $C \beta 2$ gene in mice (58). With the existing data we cannot eliminate more complicated models. For instance, one of the RFLPs reported here may be in linkage disequilibrium with a variable coding exon and the other with a polymorphic regulatory element, making the combination of the RFLPs a marker for an extended region of the TCR $\beta$ genes.

Our observation of a strong association between the TCR $\beta$ and the HLA-DQ1 serotype in Ro(SSA) precipitin-positive patients is particularly interesting in light of recent studies of HLA-D antigens and the presence of this autoantibody. Hamilton et al. (15) found a significant association with DR2 (and DQ1 with which it is in linkage disequilibrium) but not DR3 (or DQ2) in SLE patients with the Ro(SSA) but not the $\mathrm{La}$ (SSB) antibodies, again suggesting that it is this group of patients that may be responsible for these findings. However, using stepwise logistic regression analysis in this and other reports $(15,17), \mathrm{DQ} 1 / \mathrm{DQ} 2$ heterozygosity has been most strongly associated with anti-Ro(SSA) antibodies. Together with data presented here, these findings allow us to expand upon a previous model suggesting a requirement for gene complementation between HLA-DQ1 (or DR2) and HLADQ2 (DR3) associated polypeptides for the presentation of the Ro(SSA) antigen in lupus and Sjogren's syndrome patients $(14,15,17)$, to include T cells whose TCR $\beta$ polypeptide in part recognizes an HLA-DQ1-associated antigen complex. This proposal contradicts data from Kotzin and Palmer (59), which showed that mouse MHC but not TCR genes are important in the production of antinuclear antibodies and proteinurea in the $(\mathrm{NZB} \times \mathrm{NZW}) \mathrm{F} 1$ model of lupus. However, this proposal is in agreement with three other reports of murine autoimmune disease models. Using the same animal model as Kotzin and Palmer, Yanagi et al. found that both MHC and TCR $\beta$ genes are important in the development of IgG anti-DNA antibodies and circulating gp70 immune complexes (60). Ghatak et al. (61) reported that both MHC and TCR $\beta$ genes are associated with nephritis in (NZB $\times$ SWR)F1 mice, an autoimmune model with different TCR mutations than that mentioned above (62), Finally, the susceptibility to collagen-induced arthritis in $(\mathrm{B} 10 \times \mathrm{SWR}) \mathrm{F} 1$ hybrid mice has recently been shown to be associated with particular MHC and TCR $\beta$ gene usage by Banerjee et al. (57). These data suggest that restricted expression of TCR $\beta$ genes in the presence of appropriate MHC gene products may be necessary for the development of particular aspects of autoimmunity.

The ability to appreciate the genetic complexity of lupus may lie in subdividing patients into relatively homogeneous groups for study. The use of specific autoantibodies in this report is a classification scheme that appears to have pathophysiologic relevance. Recent studies have demonstrated a high frequency of anti-Ro(SSA) antibodies in first degree relatives of anti-Ro(SSA)-positive SLE patients when compared with controls (63). Data from Arnett et al. suggest that both MHC and non-MHC genes are important in this immune response (64). The data presented here provide the first direct evidence for a specific, non-MHC gene involved in the regulation of anti-Ro(SSA) autoantibodies. These data are the first to show an association between a TCR gene and a known human autoantigen, and are consistent with a model proposing that genes at multiple immune response loci determine the presence of particular antibodies in lupus patients, which in turn lead to the differential manifestations of this disease $(17,65)$.

\section{Acknowledgments}

We gratefully acknowledge Dr. J. D. Capra of the University of Texas Southwestern Medical Center at Dallas for providing a human TCR cDNA clone, and Laurie Soares for excellent technical assistance in isolating and subcloning the TCR C $\beta$ region used in this work.

This work was supported by grants from the Oklahoma Lupus Foundation, the Lupus Foundation of America, Public Health Service grants AI-24717 and AR-39577, the March of Dimes Birth Defects Foundation (1-1109), and the Veteran's Administration. Dr. Frank is an Alumni Research Scholar of the University of Oklahoma College of Medicine.

\section{References}

1. Leonhardt, T. 1964. Family studies in systemic lupus erythematosus. Acta Med. Scand. 176:1-136.

2. Arnett, F. C., and L. E. Shulman. 1976. Studies in familial systemic lupus erythematosus. Medicine (Baltimore). 55:313-322.

3. Block, S. R., J. B. Winfield, M. D. Lockshin, W. A. D'Angelo, and C. L. Christian. 1975. Studies of twins with systemic lupus erythematosus: a review of the literature and presentation of 12 additional sets. Am. J. Med. 59:533-552.

4. Block, S. R., M. D. Lockshin, J. B. Winfield, M. E. Weksler, I. Masakatsu, R. J. Winchester, R. C. Mellors, and C. L. Christian. 1976. Immunologic observations on 9 sets of twins either concordant or discordant for SLE. Arthritis Rheum. 19:545-554. 
5. Tiwari, T. L., and P. I. Terasaki. 1985. In HLA and Disease Associations. Springer-Verlag New York Inc., New York. 363-385.

6. Grumet, F. C., A. Coukel, J. C. Bodmer, W. F. Bodmer, and H. O. McDevitt. 1971. Histocompatibility (HL-A) antigens associated with systemic lupus erythematosus. $N$. Engl. J. Med. 285:193-196.

7. Wilson, W. A., E. Scopetilis, and J. P. Michalski. 1984. Association of the HLA-DR7 with both antibody to SSA(Ro) and disease susceptibility in blacks with systemic lupus erythematosus. J. Rheumatol. 11:653-657.

8. Howard, P. F., M. C. Hochberg, W. B. Bias, F. C. Arnett, and R. H. McLean. 1986. Relationship between C4 null genes, HLA-D region antigens, and antigen susceptibility to systemic lupus erythematosus in Caucasian and Black Americans. Am. J. Med. 81:187-193.

9. Kemp, M. E., J. P. Atkinson, V. M. Skanes, R. P. Levine, and D. D. Chaplin. 1987. Deletion of C4A genes in patients with systemic lupus erythematosus. Arthritis Rheum. 30:1015-1022.

10. Goldstein, R., F. C. Arnett, R. H. McLean, W. B. Bias, and M. Duvic. 1988. Molecular heterogeneity of complement component $C 4$ null and 21-hydroxylase genes in systemic lupus erythematosus. $A r$ thritis Rheum. 31:736-744.

11. Arnett, F. C., R. Goldstein, M. Duvic, and J. D. Reveille. 1988. Major histocompatibility complex genes in systemic lupus erythematosus, Sjogren's syndrome, and polymyositis. Am. J. Med. 85:38-41.

12. Fielder, A. H. L., M. J. Walport, J. R. Batchelor, R. I. Rynes, C. M. Black, I. A. Dodi, and G. R. V. Hughes. 1983. Family studies of the major histocompatibility complex in patients with systemic lupus erythematosus: importance of null alleles of C4A and C4B in determining disease susceptibility. Br. Med. J. 286:425-428.

13. Revielle, J. D., F. C. Arnett, R. W. Wilson, W. B. Bias, and R. H. McLean. 1985. Null alleles of the fourth component of complement and HLA haplotypes in familial systemic lupus erythematosus. Immunogenetics. 21:299-311.

14. Harley, J. B., M. Reichlin, F. C. Arnett, E. L. Alexander, W. B. Bias, and T. T. Provost. 1986. Gene interaction at HLA-DQ enhances autoantibody production in primary Sjogren's syndrome. Science (Wash. DC). 232:1145-1147.

15. Hamilton, R. G., J. B. Harley, W. B. Bias, M. Roebber, M Reichlin, M. C. Hochberg, and F. C. Arnett. 1988. Two Ro (SS-A) autoantibody responses in systemic lupus erythematosus: correlation of HLA-DR/DQ specificities with quantitative expression of Ro (SS-A) autoantibody. Arthritis Rheum. 31:496-505.

16. Hochberg, M. C., R. E. Boyd, Jr., J. M. Ahearn, F. C. Arnett, W. B. Bias, T. T. Provost, and M. B. Stevens. 1985. Systemic lupus erythematosus: a review of clinico-laboratory features and immunogenetic markers in 150 patients with emphasis on demographic subsets. Medicine (Baltimore). 64:285-295.

17. Harley, J. B., A. L. Sestak, L. G. Willis, S. M. Fu, J. A. Hansen, and M. R. Reichlin. 1989. A model for disease heterogeneity in systemic lupus erythematosus: relationships between histocompatibility antigens, autoantibodies, lymphopenia or renal disease. Arthritis Rheum. 32:826-836.

18. Bell, D. A., and P. J. Maddison. 1980. Serologic subsets in systemic lupus erythematosus. Arthritis Rheum. 23:1268-1273.

19. Clark, G., M. Reichlin, and T. B. Thomas, Jr. 1969. Characterization of a soluble cytoplasmic antigen reactive with sera from patients with systemic lupus erythematosus. J. Immunol. 102:117-122.

20. Lerner, M. R., J. A. Boyle, J. A. Hardin, and J. A. Steitz. 1981. Two normal classes of small ribonucleoproteins detected by antibodies associated with lupus erythematosus. Science (Wash. DC). 211:400402.

21. Reichlin, M. 1986. Significance of the Ro antigen system. $J$. Clin. Immunol. 6:339-348.

22. Alspaugh, M. A., and E. M. Tan. 1975. Antibodies to cellular antigens in Sjogren's syndrome. J. Clin. Invest. 55:1067-1073.

23. Harley, J. B., E. L. Alexander, W. B. Bias, O. F. Fox, T. T. Provost, M. Reichlin, H. Yamogata, and F. C. Arnett. 1986. Anti-Ro/ SSA and anti-La/SSB in patients with Sjogren's syndrome. Arthritis Rheum. 29:196-206.
24. Wasicek, C. A., and M. Reichlin. 1982. Clinical and serological differences between systemic lupus erythematosus patients with antibodies to Ro versus patients with antibodies to Ro and La. J. Clin. Invest. 69:835-843.

25. Mond, C. B., M. G. E. Peterson, and N. F. Rothfield. 1989. Correlation of anti-Ro antibody with photosensitivity skin rash in systemic lupus erythematosus. Arthritis Rheum. 32:202-204.

26. Maddison, P. J., H. Mogavero, T. T. Provost, and M. Reichlin. 1979. The clinical significance of antibodies to a soluble cytoplasmic antigen in SLE and other connective tissue diseases. J. Rheumatol. 6:189-195.

27. Smolen, J. S., C. Morimoto, A. D. Steinberg, A. Wolf, S. F. Schlossman, R. T. Steinberg, E. Penner, E. Reinherz, M. Reichlin, and T. M. Chused. 1985. Systemic lupus erythematosus: delineation of subpopulations by clinical, serologic and T cell subset analysis. Am. J. Med. Sci. 289:139-147.

28. Maddison, P. J., and M. Reichlin. 1979. Deposition of antibodies to a soluble cytoplasmic antigen in the kidneys of patients with systemic lupus erythematosus. Arthritis Rheum. 22:858-863.

29. Lee, L. A., K. K. Gaither, S. Coulter, D. A. Norris, and J. B. Harley. 1989. The pattern of cutaneous IgG deposition in a case of subacute cutaneous lupus erythematosus is reproduced by infusing purified anti-Ro(SSA) autoantibodies into human skin-grafted mice. $J$. Clin. Invest. 83:1556-1562.

30. Scott, J. S., P. J. Maddison, P. V. Taylor, E. Esscher, O. Scott, and R. P. Skinner. 1983. Connective tissue disease, antibodies to ribonucleoprotein and congenital heart block. N. Engl. J. Med. 309:209212.

31. Watson, R. M., A. T. Lane, N. K. Barnett, W. B. Bias, F. C. Arnett, and T. T. Provost. 1984. Neonatal lupus erythematosus: a clinical, serological and immunogenetic study with review of the literature. Medicine (Baltimore). 63:362-378.

32. Taylor, P. V., K. F. Taylor, A. Norman, S. Griffiths, and J. S. Scott. 1988. Prevalence of maternal Ro(SSA) and $\mathrm{La}(\mathrm{SSB})$ autoantibodies in relation to congenital heart block. Br. J. Rheumatol. 27:128-132.

33. Kassan, S. S., M. Akizuki, A. D. Steinberg, R. L. Reddick, and T. M. Chused. 1977. Antibody to soluble acidic nuclear antigen in Sjogren's syndrome. Am. J. Med. 63:328-355.

34. Alspaugh, M. A., W. W. Buchanan, and K. Whaley. 1978. Precipitating antibodies to cellular antigens in Sjogren's syndrome, rheumatoid arthritis, and other organ and nonorgan-specific autoimmune disease. Ann. Rheum. Dis. 37:244-247.

35. Sontheimer, R. D., P. J. Maddison, M. Reichlin, R. E. Jordan, P. Stastny, and J. N. Gilliam. 1982. Serologic and HLA associations in subacute cutaneous lupus erythematosus, a clinical subset of lupus erythematosus. Ann. Intern. Med. 97:664-671.

36. Alexander, E. L., T. J. Hirsh, F. C. Arnett, T. T. Provost, and M. B. Stevens. 1982. $\mathrm{Ro}(\mathrm{SSA})$ and $\mathrm{La}(\mathrm{SSB})$ antibodies in the clinical spectrum of Sjogren's syndrome. J. Rheumatol. 9:239-246.

37. Fronek, Z., D. Lentz, N. Berliner, A. D. Duby, K. A. Klein, J. G. Seidman, and P. H. Schur. 1986. Systemic lupus erythematosus is not genetically linked to the beta chain of the T cell receptor. Arthritis Rheum. 29:1023-1025.

38. Dunckley, H., P. A. Gatenby, and S. W. Serjeantson. 1988. T-cell receptor and HLA class II RFLPs in systemic lupus erythematosus. Immunogenetics. 27:393-395.

39. Wong, D. W., Z. Bentwich, C. Martinez-Tarquino, J. G. Seidman, A. D. Duby, T. Quertermons, and P. H. Schur. 1988. Nonlinkage of the $\mathrm{T}$ cell receptor alpha, beta, and gamma genes to systemic lupus erythematosus in multiplex families. Arthritis Rheum. 31:1371-1376.

40. Yanagi, Y., Y. Yoshikai, K. Legett, S. P. Clark, I. Aleksander, and T. Mak. 1984. A human T-cell specific cDNA clone encodes a protein having extensive homology to immunoglobulin chains. Nature (Lond.). 308:145-149.

41. Cohen, S. N., A. C. Y. Chang, and L. Hsu. 1969. Nonchromosomal antibiotic resistance in bacteria: genetic transformation of Escherichia coli. Proc. Natl. Acad. Sci. USA. 69:2110-2114. 
42. Tan, E. M., A. S. Cohen, J. F. Fries, A. T. Masi, D. J. McShane, N. F. Rothfield, J. G. Schaller, N. Talal, and R. J. Winchester. 1982. The 1982 revised criteria for the classification of systemic lupus erythematosus. Arthritis Rheum. 25:1271-1277.

43. Southern, E. M. 1978. Detection of specific sequences among DNA fragments separated by gel electrophoresis. J. Mol. Biol. 98:503-517.

44. Feinberg, A. P., and B. Vogelstein. 1983. A technique for radiolabeling DNA restriction endonuclease fragments to high specific activity. Anal. Biochem. 132:6-13.

45. Feinberg, A. P., and B. Vogelstein. 1984. Addendum: a technique for radiolabeling DNA restriction endonuclease fragments to high specific activity. Anal. Biochem. 137:266-267.

46. Robinson, M. A., and T. J. Kindt. 1985. Segregation of polymorphic T-cell receptor genes in human families. Proc. Natl. Acad. Sci. USA. 82:3804-3808.

47. Oksenberg, J. R., C. N. Gaiser, L. L. Cavalli-Sforza, and L. Steinman. 1988. Polymorphic markers of human T-cell receptor alpha and beta genes: family studies and comparison of frequencies in healthy individuals and patients with multiple sclerosis and myasthenia gravis California 94305. Hum. Immunol. 22:111-121.

48. Berliner, N., A. D. Duby, C. C. Morton, P. Leder, and J. G. Seidman. 1985. Detection of a frequent restriction fragment length polymorphism in the human $\mathrm{T}$ cell antigen receptor beta chain locus. J. Clin. Invest. 76:1283-1285.

49. Toyonaga, B., Y. Yoshikai, V. Vadasz, B. Chin, and T. Mak. 1985. Organization and sequences of the diversity, joining, and constant region genes of the human T-cell receptor beta chain. Proc. Natl. Acad. Sci. USA. 82:8624-8628.

50. Rupp, F., J. Brecher, M. A. Giedlin, T. Mosmann, R. M. Zinkernagel, H. Hengartner, and R. H. Joho. 1987. T-cell antigen receptors with identical variable regions but different diversity and joining region gene segments have distinct specificities but cross-reactive idiotypes. Proc. Natl. Acad. Sci. USA. 84:219-222.

51. Robinson, M. A., and T. J. Kindt. 1986. Molecular genotyping of human T-cell antigen receptor variable gene segments. Immunogenetics. 24:259-266.

52. Concannon, P., R. A. Gatti, and L. E. Hood. 1987. Human T cell receptor V beta gene polymorphism. J. Exp. Med. 165:1130-1140.

53. Kronenberg, M., G. Siu, L. E. Hood, and N. Shastri. 1986. The molecular genetics of the T-cell antigen receptor and T-cell antigen recognition. Annu. Rev. Immunol. 4:529-591.

54. Acha-Orbea, H., L. Steinman, and H. O. McDevitt. 1989. T cell receptors in murine autoimmune diseases. Annu. Rev. Immunol. 7:371-405.

55. Urban, J. L., V. Kumar, D. H. Kono, C. Gomez, S. J. Horvath, J. Clayton, D. G. Ando, E. E. Sercarz, and L. Hood. 1988. Restricted use of $T$ cell receptor $V$ genes in murine autoimmune encephalomyelitis raises possibilities for antibody therapy. Cell. 54:577-592.

56. Acha-Orbea, H., D. J. Mitchell, L. Timmermann, D. C. Wraith, G. S. Tausch, M. K. Waldor, S. S. Zamvil, H. O. McDevitt, and $L$. Steinman. 1988. Limited heterogeneity of T cell receptors from lymphocytes mediating autoimmune encephalomyelitis allows specific immune intervention. Cell. 54:263-273.

57. Banerjee, S., T. M. Haqqi, H. S. Luthra, J. M. Stuart, and C. S. David. 1988. Possible role of $\mathrm{V}$ beta $\mathrm{T}$ cell receptor genes in susceptibility to collagen-induced arthritis in mice. J. Exp. Med. 167:832-839.

58. Krimpenfort, P., R. de Jong, Y. Uematsu, Z. Dembic, S. Ryser, H. von Boehmer, M. Steinmetz, and A. Berns. 1988. Transcription of $\mathrm{T}$ cell receptor beta-chain genes is controlled by a downstream regulatory element. EMBO (Eur. Mol. Biol. Organ.) J. 7:745-750.

59. Kotzin, B. L., and E. Palmer. 1987. The contribution of NZW genes to lupus-like disease in $(\mathrm{NZB} \times \mathrm{NZW}) \mathrm{F} 1$ mice. J. Exp. Med. 165:1237-1251.

60. Yanagi, Y., S. Hirose, R. Nagasawa, T. Shirai, T. W. Mak, and $T$. Tada. 1986. Does the deletion within $T$ cell receptor beta-chain gene of NZW mice contribute to autoimmunity in $(\mathrm{NZB} \times \mathrm{NZW}) \mathrm{F} 1$ mice? Eur. J. Immunol. 16:1179-1182.

61. Ghatak, S., K. Sainis, F. L. Owen, and S. K. Datta. 1987. T-cell-receptor beta- and I-A beta-chain genes of normal SWR mice are linked with the development of lupus nephritis in NZB $\times$ SWR crosses. Proc. Natl. Acad. Sci. USA. 84:6850-6853.

62. Kotzin, B. L., V. L. Barr, and E. Palmer. 1985. A large deletion within the T-cell receptor beta-chain gene complex in New Zealand white mice. Science (Wash. DC). 229:167-171.

63. Lehman, T. J. A., V. Hanson, N. Zvaifler, G. Sharp, and M. Alspaugh. 1984. Antibodies to nonhistone nuclear antigen and antilymphocyte antibodies among children and adults with systemic lupus erythematosus. J. Rheumatol. 11:644-647.

64. Arnett, F. C., R. G. Hamilton, W. B. Bias, J. D. Reveille, J. B. Harley, and M. Reichlin. 1989. Genetic studies of Ro(SS-A) and $\mathrm{La}(\mathrm{SS}-\mathrm{B})$ autoantibodies detected by ELISA in families with systemic lupus erythematosus and primary Sjogren's syndrome. Arthritis Rheum. 32:413-419.

65. Harley, J. B., and K. K. Gaither. 1988. Autoantibodies. Rheum. Dis. Clin. North Am. 14:43-56. 